\title{
A unique bilateral variation of lateral atlantoaxial joint meniscoid morphology: case report
}

\author{
Subaat Khan ${ }^{1,2}$, Scott F. Farrell ${ }^{1}$ \\ ${ }^{1}$ RECOVER Injury Research Centre, Griffith University, Southport, Queensland, Australia \\ ${ }^{2}$ School of Medical Science, Griffith University, Southport, Queensland, Australia
}

\begin{abstract}
Advances in understanding of the anatomy of lateral atlantoaxial joint meniscoids have lead to theories regarding the clinical significance of these structures in head and neck pain. However, there is a paucity of evidence pertaining to anatomical variations of lateral atlantoaxial joint meniscoids in cadaveric research or in vivo. We present the case of a 57-year-old female with a variation in the morphology of the lateral atlantoaxial joint meniscoids. The subject was a symptom-free volunteer in an anatomical study employing magnetic resonance imaging. On review of her scans, the dorsal meniscoid of both left and right lateral atlantoaxial joints extended across the entirety of the articular cavities, with no visible ventral meniscoid. This variation has not previously been reported, and may have clinical implications in the context of cervical spine trauma. With increasing evidence regarding the pathoanatomical potential of lateral atlantoaxial joint meniscoids, appreciation of anatomical variation in a symptom-free population may have future clinical utility.
\end{abstract}

Keywords: anatomy; atlantoaxial joint; cervical spine; meniscoid; synovial folds

Anatomy 2016;10(2):153-155 @2016 Turkish Society of Anatomy and Clinical Anatomy (TSACA)

\section{Introduction}

Lateral atlantoaxial joint meniscoids, also known as synovial folds, are invaginations of synovial membrane that extend between the articular surfaces. ${ }^{[1,2]}$ These structures are found at the ventral and dorsal aspects of lateral atlantoaxial joints (Figure 1), and are hypothesized to function to ensure lubrication of articular surfaces with synovial fluid and aid in distribution of weight through the joint. ${ }^{[2-5]}$ Lateral atlantoaxial joint meniscoids comprise adipose tissue, fibrous tissue, or a combination of both tissue types, and have been noted to contain blood vessels and nerve fibres. ${ }^{[1,6]}$

Lateral atlantoaxial joint meniscoids have been theorised to be of clinical significance through their fibrosis or degeneration, mechanical entrapment between articular surfaces, or injury during cervical spine trauma, such as in a whiplash injury. ${ }^{[2]}$ Recent findings of an MRI study $^{[7]}$ suggest that meniscoid morphology may have clinical implications in chronic whiplash neck pain. Consequently, recognition of variability in meniscoid anatomy is of potential interest to both anatomical scientists and clinicians.

\section{Case Report}

We present the case of a 57-year-old female that volunteered to participate in a university research project examining cervical spine morphology in whiplash-associated disorder. The subject had volunteered as a member of the pain-free control group for the project, and as such had no history of significant cervical spine pain, trauma or surgery, no known congenital cervical spine deformities, no history of rheumatic disorders and no other significant medical history. Written informed consent was attained prior to participation in the project. The study received institutional human research ethics approval and was undertaken in accordance with the ethical standards laid down in the Declaration of Helsinki. 
The subject underwent cervical spine magnetic resonance imaging in 3-Tesla unit (Siemens AG, Munich, Germany) with a 20-channel head and neck coil using a T1-weighted volumetric inter-polated breath-hold examination (T1-VIBE) sequence with fat suppression. This sequence was selected to effectively visualize the lateral atlantoaxial and cervical zygapophyseal joints and their enclosed meniscoids, and was modified from a protocol described by Friedrich et al. ${ }^{[8]}$

On review of the scans, it was noted that both the left and right lateral atlantoaxial joints appeared to each contain one large meniscoid only, rather than two distinct meniscoids at the ventral and dorsal aspects of the each joint. These structures extended from the joint capsule at the dorsal aspect of the joint, through the articular cavity to the ventral aspect of the joint, almost reaching the ventral joint capsule (Figure 2). In both the left and right lateral atlantoaxial joints, the large dorsal meniscoids were visible at the medial, central and lateral aspects of the joints. At their widest points, both dorsal meniscoids measured $1.4 \mathrm{~cm}$ in a posterior-anterior direction from joint capsule to apex.

\section{Discussion}

On review of the literature regarding lateral atlantoaxial meniscoid morphology, no prior work has explicitly reported the variation described in the present case study: dorsal meniscoids spanning the lateral atlantoaxi-

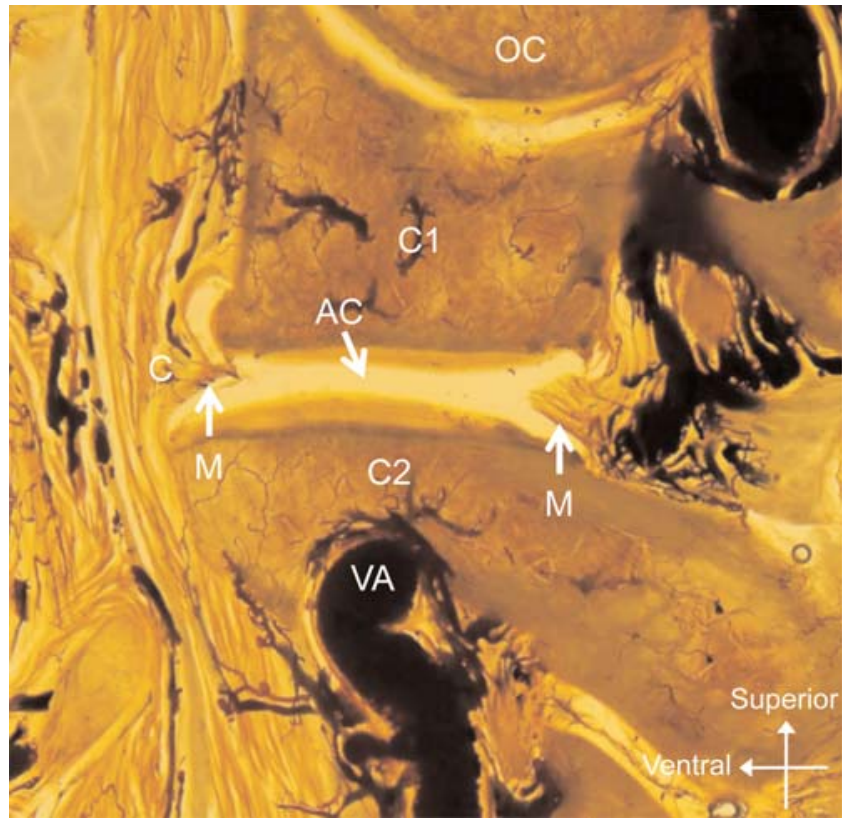

Figure 1. Lateral atlantoaxial joint of a sagittally sectioned sheet plastinated cadaver. Meniscoids are present at the ventral and dorsal aspects of the joint. AC: articular cavity; C: capsule; M: meniscoid; OC: occipital condyle; VA: vertebral artery. Modified from Farrell et al ${ }^{[12]}$ [Color figure can be viewed in the online issue, which is available at www.anatomy.org.tr]

al joints, in lieu of ventral meniscoids. Such an absence of prior description may infer that the observed variation is reasonably uncommon.
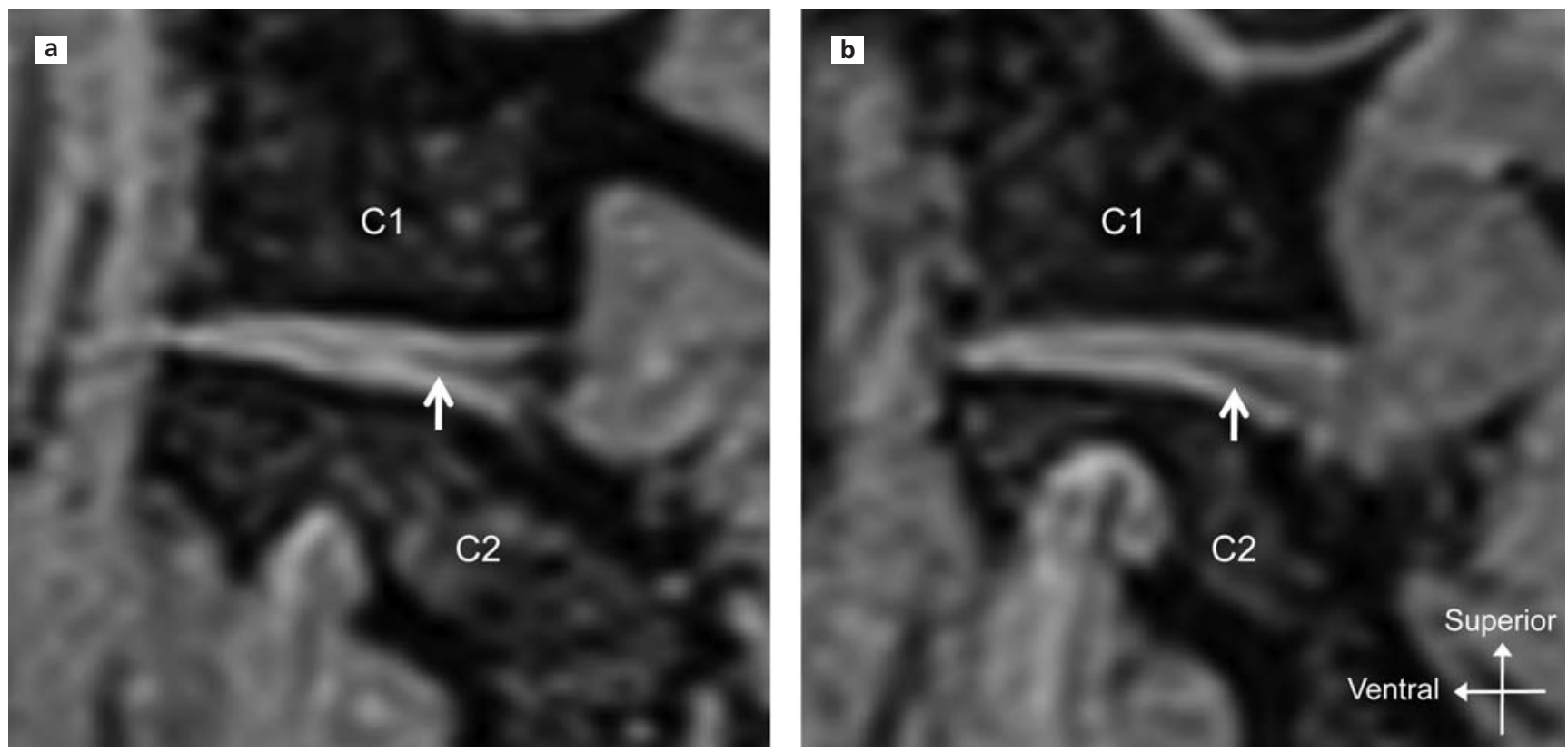

Figure 2. Sagittal magnetic resonance imaging of (a) left and (b) right lateral atlantoaxial joints (T1-VIBE sequence with fat suppression). In both (a) and (b) the dorsal meniscoid (white arrow) extends to the ventral aspect of the joint, and there is no apparent ventral meniscoid. 
It is plausible that the observed variation may have an embryological origin. The spinal meniscoids are theorized to originate as single mesenchymal plates that span the primitive articular cavities of spinal joints. ${ }^{[2,9]}$ As the embryo develops, each plate is thought to undergo a regressive process leading to attrition of the central portion of the structure, such that wedges of tissue remain at the peripheries of the joints, forming ventral and dorsal meniscoids. ${ }^{[2,3,9]}$ Variation in the regression of the primitive lateral atlantoaxial joint mesenchymal plates may have lead to the unusually large dorsal meniscoids and absent ventral meniscoids noted in the present case, however, this is a speculative explanation.

The existence of dorsal meniscoids spanning the lateral atlantoaxial joints may have clinical significance for people with this anatomical variation. Lateral atlantoaxial joint meniscoids have been implicated as structures capable of being damaged during cervical spine trauma, by autopsy evidence of contusion and haematoma in victims of fatal motor vehicle collisions. ${ }^{[10,11]}$ It is plausible that a large meniscoid occupying a significant portion of the articular cavity may be more easily impacted between the enveloping articular surfaces than a smaller meniscoid, and as such one may speculate that the variation described in the present case report may be associated with a higher likelihood of meniscoid injury if the individual were subject to significant cervical spine trauma.

Understanding of the clinical significance of lateral atlantoaxial joint meniscoids is increasing, with recent research noting associations between meniscoid morphology and articular degeneration, ${ }^{[1]}$ describing their innervation, ${ }^{[6]}$ and observing morphometrical differences between lateral atlantoaxial joint meniscoids of individuals with chronic whiplash associated disorder and matched asymptomatic controls. ${ }^{[7]}$ With advances in magnetic resonance imaging, our capacity to visualize lateral atlantoaxial joint meniscoids in vivo is improving, and as such it is important to be aware of variations in the anatomy of these potentially clinically significant structures.

\section{References}

1. Farrell SF, Osmotherly PG, Cornwall J, Rivett DA. Morphology and morphometry of lateral atlantoaxial joint meniscoids. Anat Sci Int 2016;91:89-96.

2. Webb AL, Collins P, Rassoulian H, Mitchell BS. Synovial folds - a pain in the neck? Man Ther 2011;16:118-24.

3. Mercer S, Bogduk N. Intra-articular inclusions of the cervical synovial joints. Br J Rheumatol 1993;32:705-10.

4. Webb AL, Rassoulian H, Mitchell BS. Morphometry of the synovial folds of the lateral atlanto-axial joints: the anatomical basis for understanding their potential role in neck pain. Surg Radiol Anat 2012;34:115-24.

5. Webb AL, Darekar AA, Sampson M, Rassoulian H. Synovial folds of the lateral atlantoaxial joints: in vivo quantitative assessment using magnetic resonance imaging in healthy volunteers. Spine (Phila $\mathrm{Pa}$ 1976) 2009;34:E697-702.

6. Farrell SF, Osmotherly PG, Cornwall J, Rivett DA. Immunohistochemical investigation of nerve fibre presence and morphology in elderly cervical spine meniscoids. Spine J 2016 Jun 11. doi: 10.1016/j.spinee.2016.06.004.

7. Farrell SF, Osmotherly PG, Cornwall J, Lau P, Rivett DA. Morphology of cervical spine meniscoids in individuals with chronic whiplash associated disorder: a case-control study. J Orthop Sports Phys Ther 2016 (in press).

8. Friedrich KM, Reiter G, Pretterklieber ML, Pinker K, Friedrich M, Trattnig S, Salomonowitz E. Reference data for in vivo magnetic resonance imaging properties of meniscoids in the cervical zygapophyseal joints. Spine (Phila Pa 1976) 2008;33:E778-83.

9. Engel R, Bogduk N. The menisci of the lumbar zygapophsial joints. J Anat 1982;135:795-809.

10. Schonstrom N, Twomey L, Taylor J. The lateral atlanto-axial joints and their synovial folds: an in vitro study of soft tissue injuries and fractures. J Trauma 1993;35:886-92.

11. Taylor JR, Taylor MM. Cervical spine injuries: an autopsy of 109 blunt injuries. J Musculoskelet Pain 1996;4:61-79.

12. Farrell SF, Osmotherly PG, Rivett DA, Cornwall J. Can E12 sheet plastination be used to examine the presence and incidence of intraarticular spinal meniscoids? Anatomy 2015;9:13-8.

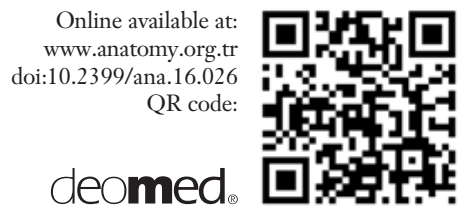

Correspondence to: Scott F. Farrell, PhD RECOVER Injury Research Centre, G05 Griffith University Southport 4222, Queensland, Australia

Phone: +617 55528169

e-mail: s.farrell@griffith.edu.au

Conflict of interest statement: No conflicts declared.

This is an open access article distributed under the terms of the Creative Commons Attribution-NonCommercial-NoDerivs 3.0 Unported (CC BY-NCND3.0) Licence (http://creativecommons.org/licenses/by-nc-nd/3.0/) which permits unrestricted noncommercial use, distribution, and reproduction in any medium, provided the original work is properly cited. Please cite this article as: Khan S, Farrell SF. A unique bilateral variation of lateral atlantoaxial joint meniscoid morphology: case report. Anatomy 2016;10(2):153-155. 